\title{
Radiotherapy or anti CD 20 antibodies as a first treatment line in splenic marginal zone lymphoma in emergent countries: the experience in Chilean population
}

\author{
Keywords: malignant, leukemias, splenectomy, lymphomas
}

Abbreviations: SMZL, splenic marginal zone lymphoma; CVP, cyclophosphamide, vincristine and prednisone; CIT, chemo immuno therapy; SR, splenic radiotherapy

\section{Opinion}

Splenic marginal zone lymphoma (SMZL) is a rare malignant condition of B cells. It usually manifests with massive splenomegaly, and has frequent bone marrow and peripheral blood involvement. ${ }^{1}$ It amounts to $5 \%$ of non-Hodgkin's lymphomas and less than $1-2 \%$ of leukemias derived from low-grade lymphomas. SMZL, however, can be found in up to $25 \%$ of lymphomas diagnosed after a splenectomy. Its course is indolent, and its symptoms are vague and related to the discomfort caused by splenomegaly and cytopenia secondary to hypersplenism. ${ }^{1-3}$

There is no standard first-line treatment in SMZL. Chemotherapy as a first line therapy has shown limited efficacy. ${ }^{2-4}$ Splenectomy, on the other hand, has been the most expeditious and effective method in reducing the size of the spleen and improving the blood cell count after its removal, and it has been suggested as the treatment of choice based on case series. ${ }^{2}$ Approximately $90 \%$ of patients respond to splenectomy. But patients suffering from this disease are often elderly, with an increased surgical risk, in addition to the complications of asplenia: capsulated bacterial infections, thromboembolic vascular events, perioperative complications, ${ }^{3-6}$ among others.

Various chemotherapy schemes have been evaluated in SMZL. These include: chlorambucil alone, cyclophosphamide, vincristine and prednisone (CVP), or the same plus doxorrubicin (CHOP). All the mentioned schemes have limited efficacy in SMZL. The limited number of patients in these studies, as well as the selection bias (patients with advanced pathology and worse prognosis are those who undergo chemotherapy), could explain the relative advantage of splenectomy over other treatments. Rituximab, a synthetic murine/ human anti-CD20 monoclonal antibody has become standard therapy for malignant B-cells neoplasm including its use alone or in combination (also called chemoimmunotherapy, CIT) for SMZL4, as well as second line therapy in other benign hematologic malignancies with splenic involvement in its pathogenesis like autoimmune hemolytic anemia and immunologic thrombocytopenic purpura. ${ }^{6}$

In the last census of the Chilean population a progressive aging and greater life expectancy of the population was detected7. This represents a major challenge, considering that many patients with splenomegaly secondary to low-grade lymphoproliferative syndromes such as SMZL, will not be suitable candidates for chemoimmunotherapy or splenectomy. In this scenario, available treatments are rituximab as
Volume 2 Issue I - 2018

\author{
Demetrio Torres C,' Mauricio Chandía C, ${ }^{2}$ \\ Eugenio FVines' \\ 'Servicio de Radio-Oncología, Pontificia Universidad Católica de \\ Chile, Chile \\ ${ }^{2}$ Hematólogo, Hospital Guillermo Grand Benavente, \\ Concepción, Chile
}

Correspondence: Demetrio Elías Torres-Contreras, Centro de Cáncer "Nuestra Señora de la Esperanza", Pontificia Universidad Católica de Chile. Santiago,Address Diagonal Paraguay \#319, Santiago, Chile, Email eliastorresmd@gmail.com

Received: December 24, 2017| Published: January 08, 2018

monotherapy and splenic radiotherapy (SR). However, there are, no published studies comparing both therapies.

Regarding the use of rituximab in this type of patients, the experience published in Chile is scarced. ${ }^{1,8}$ Vega et al. ${ }^{8}$ report the a 79-year-old splenectomized patient with relapsing SMZL, and type B lactic acidosis, who had an excellent response to rituximab monotherapy, improving blood cell counts and significantly decrease in lactate from the first dose of the antibody8. We reported a 62-yearold patient with 4 years of progressive increase in abdominal girth and heart failure. On physical examination he had massive splenomegaly and pancytopenia. Peripheral blood flow cytometry demonstrated SMZL. Because of the high surgical risk, and lack of access to radiation therapy, he was treated with, rituximab monotherapy, with significant regression in spleen size, as well as sustained improvement in hematological parameters. ${ }^{1}$ Rituximab administration is possible on an outpatient basis, but considering the high tumor load in untreated patients, it is recommended to administer the first dose as a longer infusion. In our environment, this often means hospitalization, since public hospitals lack extended-day ambulatory therapy units (day hospitals), that could allow adequate supervision of the administration of the monoclonal antibody. On the other hand, the shortage of hospital beds present in Chile can mean in some cases delays in the administration of this therapy.

Traditionally, splenic radiotherapy (SR) has been considered part of the standard management in diverse types of lymphomas. Several studies suggest that delay or omission of radiation therapy in these lymphomas may have a negative impact on survival4. Although, international guidelines define radiotherapy as initial treatment of SMZL, the therapy has been privileged by systemic treatment, in spite of demonstrated the survival benefit of radiotherapy (with or without systemic therapy) in univariate analysis, remaining as a standard treatment in this pathology. ${ }^{4}$ 
In the Chilean population there is no published experience regarding the use of SR in this group of patients, but in the experience of the authors, it is an adequate alternative for patients unfit for chemoinmunotherapy (CIT) or splenectomy. The outpatient administration, the low radiation doses used and the absence of significant adverse reactions, offers important comparative advantages for our health system over the use of rituximab alone. Also, splenic radiotherapy is an effective palliative treatment of patients with splenomegaly secondary to low-grade lymphomas that have relapsed after several CIT lines. The cost of treatments varies from country to country, but palliative rituximab may amount to three to four times the cost of palliative radiotherapy., ${ }^{9,10}$ In Chilean public hospitals, four cycles of rituximab cost 10 to 20 times more than palliative radiotherapy, thus making radiotherapy an affordable treatment option.

In the future, it is necessary to perform comparative studies or publication of series of patients in emerging countries, which allow defining the role of SR over other treatments in the group of patients unfit for CIT or splenectomy as therapy for splenomegaly derived from low-grade lymphomas, especially SMZL.

\section{Acknowledgements}

None.

\section{Conflict of interest}

The author declares no conflict of interest.

\section{References}

1. Torres D, Chandía M. Linfoma esplénico de zona marginal como causa de esplenomegalia masiva. Reporte de caso clínico y revisión de la literatura. Rev Med Maule. 2012;28(1):35-39.
2. Else M, Marín-Niebla A, de la Cruz F, et al. Rituximab, used alone or in combination, is superior to other treatment modalities in splenic marginal zone lymphoma. Br J Haematol. 2012;159(3):322-328.

3. Piris MA, Mollejo M, Campo E, et al. A marginal zone pattern may be found in different varieties of non-Hodgkin's lymphoma: the morphology and immunohistology of splenic involvement by B-cell lymphomas simulating splenic marginal zone lymphoma. Histopathology. 1998;33(3):230-239.

4. Ling DC, Vargo JA, Balasubramani GK, et al. Underutilization of radiation therapy in early-stage marginal zone lymphoma negatively impacts overall survival. Pract Radiat Oncol. 2016;6(4):e97-105.

5. Bennett M, Schechter GP. Treatment of splenic marginal zone lymphoma: Splenectomy versus rituximab. Semin Hematol. 2010; 7(2):143-147.

6. Rodeghiero F, Ruggeri M. Short- and long-term risks of splenectomy for benign haematological disorders: should we revisit the indications? $\mathrm{Br} J$ Haematol. 2012;158(1):16-29.

7. http://www.censo2017.cl/wp-content/uploads/2017/12/Presentacion Resultados_Definitivos_Censo2017.pdf

8. Vega J, Rodríguez M de L, Peña A, et al. Linfoma marginal del bazo asociado a acidosis tipo B. Caso clínico. Rev Med Chil.2012;140(2):236242.

9. Robinson TJ, Dinan MA, LI Y, et al. Longitudinal trends in cost of palliative radiation for metastatic prostate cancer. $J$ Palliat Med. $2015 ; 18: 933$

10. Danese MD, Reyes CM, Gleeson ML, et al. Estimating the population benefits and costs of rituximab therapy in the United States from 1998 to 2013 using real-world data. Med Care. 2016;54(4):343-349. 